\section{Spatial Working Memory}

Helga Peter

Marburg, Deutschland

\section{Definition}

Test für das räumliche Arbeitsgedächtnis.

Siehe auch $>$,Leistungs-, Schläfrigkeits- und Vigilanzmessung“".

\title{
Synonyme
}

SWM 